OPEN ACCESS

Edited by:

Haichang Li,

The Ohio State University,

United States

Reviewed by:

Hongwei Guo,

Guangxi Medical University, China

Panagiotis J. Vlachostergios,

Cornell University, United States

*Correspondence:

Xiang-Dong Cheng chengxd516@126.com

Wei-Dong Zhang

wdzhangy@hotmail.com

Jiang-Jiang Qin

jqin@zcmu.edu.cn

${ }^{\dagger}$ These authors have contributed equally to this work

Specialty section:

This article was submitted to Experimental Pharmacology and Drug

Discovery,

a section of the journal

Frontiers in Pharmacology

Received: 08 April 2021 Accepted: 26 April 2021

Published: 07 May 2021

Citation:

Qi S-M, Dong J, Xu Z-Y, Cheng X-D, Zhang W-D and Qin J-J (2021) PROTAC: An Effective Targeted Protein Degradation Strategy for

Cancer Therapy.

Front. Pharmacol. 12:692574. doi: 10.3389/fphar.2021.692574

\section{PROTAC: An Effective Targeted Protein Degradation Strategy for Cancer Therapy}

\author{
Si-Min $\mathrm{Qi}^{1+}$, Jinyun Dong ${ }^{2 \dagger}$, Zhi-Yuan $\mathrm{Xu}^{2}$, Xiang-Dong Cheng ${ }^{2 *}$, Wei-Dong Zhang ${ }^{3 *}$ and \\ Jiang-Jiang Qin ${ }^{1,2 *}$
}

${ }^{1}$ School of Pharmaceutical Sciences, Zhejiang Chinese Medical University, Hangzhou, China, ${ }^{2}$ The Cancer Hospital of the University of Chinese Academy of Sciences (Zhejiang Cancer Hospital), Institute of Basic Medicine and Cancer (IBMC), Chinese Academy of Sciences, Hangzhou, China, ${ }^{3}$ School of Pharmacy, Naval Medical University, Shanghai, China

Proteolysis targeting chimeric (PROTAC) technology is an effective endogenous protein degradation tool developed in recent years that can ubiquitinate the target proteins through the ubiquitin-proteasome system (UPS) to achieve an effect on tumor growth. A number of literature studies on PROTAC technology have proved an insight into the feasibility of PROTAC technology to degrade target proteins. Additionally, the first oral PROTACs (ARV-110 and ARV-471) have shown encouraging results in clinical trials for prostate and breast cancer treatment, which inspires a greater enthusiasm for PROTAC research. Here we focus on the structures and mechanisms of PROTACs and describe several classes of effective PROTAC degraders based on E3 ligases.

Keywords: PROTAC, E3 ubiquitin ligase, protein degradation, ubiquitin-proteasome system, cancer therapy

\section{INTRODUCTION}

As a traditional treatment method, chemotherapy plays an irreplaceable role in the cancer treatment process. The main disadvantages of traditional anticancer drugs are that most of them have poor selectivity and are easy to develop drug resistance (Mangal et al., 2017; Dong et al., 2020; Yuan et al., 2020). As a result, the targeted therapy of cancer has attracted people's attention (Zhou Y. et al., 2020; Qi et al., 2020; Yu et al., 2020). On this basis, the discoveries of new targets and small molecule inhibitors (SMIs) become powerful treatment strategies (Dong et al., 2018). In particular, the development of small molecule kinase inhibitors has become one of the most widely pursued fields in the process of drug discovery and has made great achievements in cancer treatment (Wu et al., 2015). However, after the success, the treatment strategy also faces the same problem of drug resistance as chemotherapy (Dong et al., 2020; Xu et al., 2020). Therefore, drug resistance is the main limitation for cancer therapy and needs to be solved urgently.

In recent years, a novel strategy that targets disease-related proteins for degradation has gained tremendous attention. Proteolysis targeting chimerics (PROTACs), also known as bivalent chemical protein degraders, are heterobifunctional molecules that degrade specific endogenous proteins through the E3 ubiquitin ligase pathway (Potjewyd et al., 2020). It structurally connects the protein of interest (POI)-binding ligand and the E3 ubiquitin ligase (E3) ligand through an appropriate linker (Buckley et al., 2015; Zhang et al., 2019; Kregel et al., 2020; Vollmer et al., 2020). The potential advantages of PROTAC technology may compensate for the shortcomings of traditional drug therapy, which promotes its rapid development (Toure and Crews, 2016; Sun and Rao, 2020). This paper focuses on introducing the mechanisms and the research progress of PROTAC technology, as well as summarizing the advantages of this degradation method. 


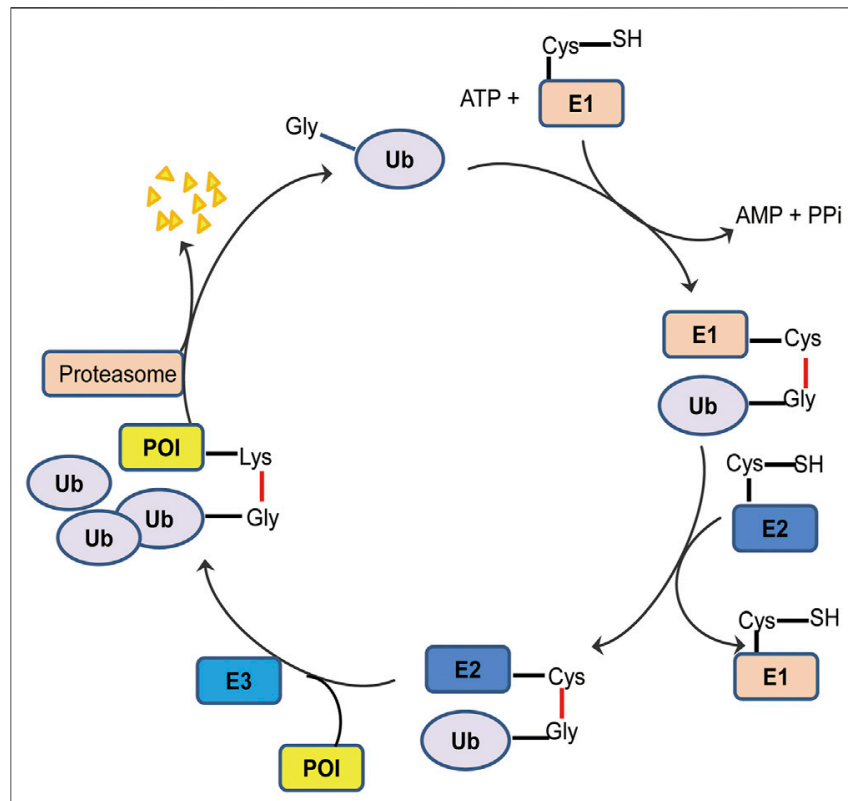

FIGURE 1 | Schematic diagram of ubiquitination process. The ubiquitin tag first binds to an E1 ubiquitin activating enzyme, transfers to an E2 ubiquitin binding enzyme, and then relies on an E3 ubiquitin ligase to deliver its ubiquitin to the target protein. Ubiquitin labeled proteins are specifically recognized and degraded by proteasome.

\section{UBIQUITIN-PROTEASOME SYSTEM AND MECHANISM OF PROTEOLYSIS TARGETING CHIMERIC TECHNOLOGY}

There are many approaches to protein degradation, which is very important to maintain the homeostasis of cell proteins and to regulate numerous cell processes, such as gene transcription, DNA pairing, cell cycle control, and apoptosis (Cyrus et al., 2011). Among them, the ubiquitin-proteasome system is a crucial way to specifically degrade proteins that are involved in various metabolic activities, mainly including cyclin, spindle related proteins, cell surface receptors (epidermal growth factor receptor, etc.), transcription factors (NF- $\kappa \mathrm{B}$, etc.), tumor suppressor factors such as $\mathrm{p} 53$, oncogene products, and intracellular denaturing proteins, whose deregulation is related to the pathogenesis of many diseases (Nam et al., 2017). UPS relies on ATP and consists of two steps: polyubiquitination of target protein and proteolysis of polyubiquitin by $26 \mathrm{~S}$ proteolytic enzyme complex (Nandi et al., 2006).

The ubiquitin-activating enzyme E1 could form a highenergy sulfur lipid bond between the C-terminal Gly residue of the ubiquitin molecule and its own Cys residue by using ATP, and the activated ubiquitin is transferred to a ubiquitin binding enzyme E2 (Zhou L. et al., 2020). In the presence of a ubiquitin ligase E3, the ubiquitin molecule transfers from E2 to the target protein, to form an isopeptide bond with $\varepsilon-\mathrm{NH}_{2}$ of the Lys residue of the target protein, and then the C-terminal of the next ubiquitin molecule connects to the former at Lys48, leading to polyubiquitination (Figure 1) (Nandi et al., 2006). The ubiquitinated protein can be recognized by the cap-like regulatory particles of $26 \mathrm{~S}$ proteasome, transported to the cylindrical core of 20S, hydrolyzed into oligopeptides by a variety of enzymes, and finally released from the proteasome to achieve the degradation of the target protein. The ubiquitin molecule, on the other hand, dissociates from the substrate and returns to the cytoplasm for reutilization (Myeku et al., 2016).

The mechanism of PROTACs is to use the UPS system to ubiquitinate and degrade the target protein (Wang et al., 2020b). Once the PROTAC molecules combine the target protein with E3 ligase together to form a ternary complex, which induces E3 ligase ubiquitinating the target protein to initiate the degradation process (Zou et al., 2019). The ubiquitinated target protein is recognized and degraded by $26 \mathrm{~S}$ proteasome, which is a part of the eukaryotic cells of UPS (Figure 2). The ability of PROTACs to induce the degradation of the target protein is not limited to the binding site within the kinase domain, and it may also be achieved when the kinase activity is not the singular action of the target protein (Burslem et al., 2019).

\section{COMPARISON AMONG PROTEOLYSIS TARGETING CHIMERICS, SMALL MOLECULE INHIBITORSS AND MONOCLONAL ANTIBODIES}

As two conventional treatment methods, SMIs and monoclonal antibodies (mAbs) have suffered from some inherent limitations, due to their ways of actions (Ohashi et al., 2013; Coats et al., 2019; Wolska-Washer and Robak, 2019; Lu et al., 2020). The SMIs can inhibit the biological activity of protein targets according to the action of specific active sites (Qin J. J. et al., 2017; Wang W. et al., 2019; Wang et al., 2020a). Until now, FDA has approved 62 SMIs that target about 20 different protein kinases (Roskoski, 2020). However, for most protein kinases, there is a lack of suitable active sites to target. In addition, molecule-targeted therapy is easy to induce drug resistance. All of these factors limit the development of SMIs in cancer treatment (Liu et al., 2020). mAbs are the highly uniform antibodies produced by a single B cell clone with high purity, high sensitivity, strong specificity, less cross reaction, and low cost. However, mAbs have a large molecular weight and mainly target proteins located at the plasma membrane. Besides, they need certain requirements for technology (Coats et al., 2019; Wolska-Washer and Robak, 2019).

The ligand of the target protein in PROTAC does not necessarily bind to the active site of the target protein, which overcomes the disadvantage of SMIs (Neklesa et al., 2017; Guo et al., 2019; Schapira et al., 2019). Owing to the existence of E3 ligase, PROTACs execute their functions by degrading the target proteins rather than inhibiting them, which is different from that of SMIs. Therefore, PROTAC has a great superiority in overcoming resistance caused by target mutation or overexpression when compared with SMIs. To date, PROTAC technology is applied to a variety of targets, including AR, ER, $\mathrm{BTK}, \mathrm{BET}$, and BCR-ABL to overcome resistance (Sun and Rao, 2020). 


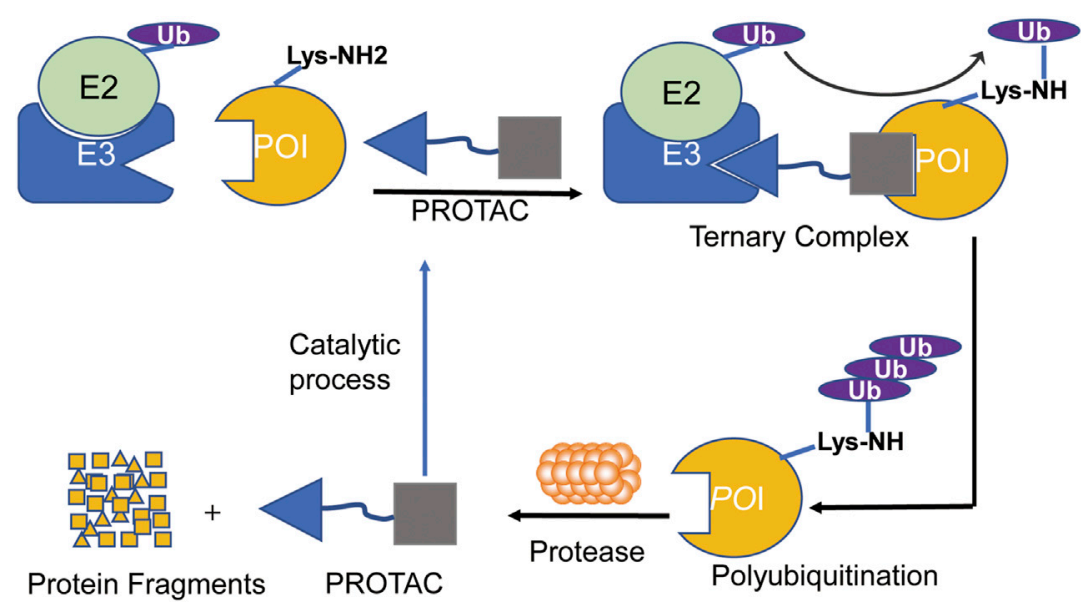

FIGURE 2 | The process of PROTAC-mediated ubiquitination and proteasomal degradation of POI. PROTAC is composed of a ligand that binds to the E3 ubiquitin ligase and a ligand that binds to the target protein through a linker, which can induce the polyubiquitination and proteasome degradation of the target proteins in cells.

TABLE 1 | Representative small-molecule PROTACs under development.

\section{PROTAC structure}

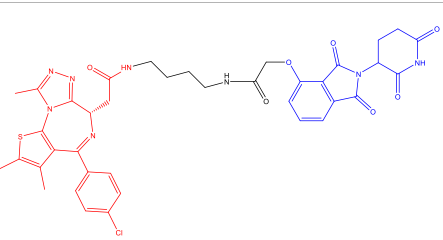

dBET1

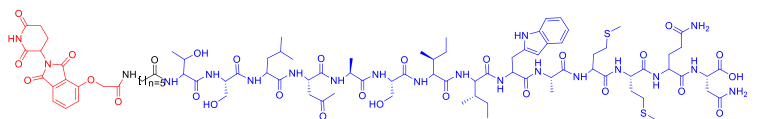

TGF- $\beta 1 \quad$ CRBN

DT-6<smiles></smiles>

CDK6

$\mathrm{Mcl}-1$

CRBN

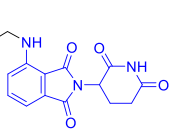

Target

E3 ligase

CRBN

CRBN

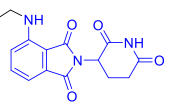

C3<smiles>CCCCC(=O)NCCN1C(=O)c2cccc3c(Sc4ccc(Br)cc4)ccc(c23)C1=O</smiles>

CRBN

BRD

CRBN

C5

$\mathrm{IC}_{50}(\mathrm{nM})$

20
$-$

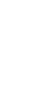

$-$

$-$

$-$
3,000 Wang et al. (2019b)

$\begin{array}{lllllllll}\text { Bcl-2 } & \text { CRBN } & - & - & & 3,000 & \text { Wang et al. (2019b) }\end{array}$


TABLE 1 | (Continued) Representative small-molecule PROTACs under development.
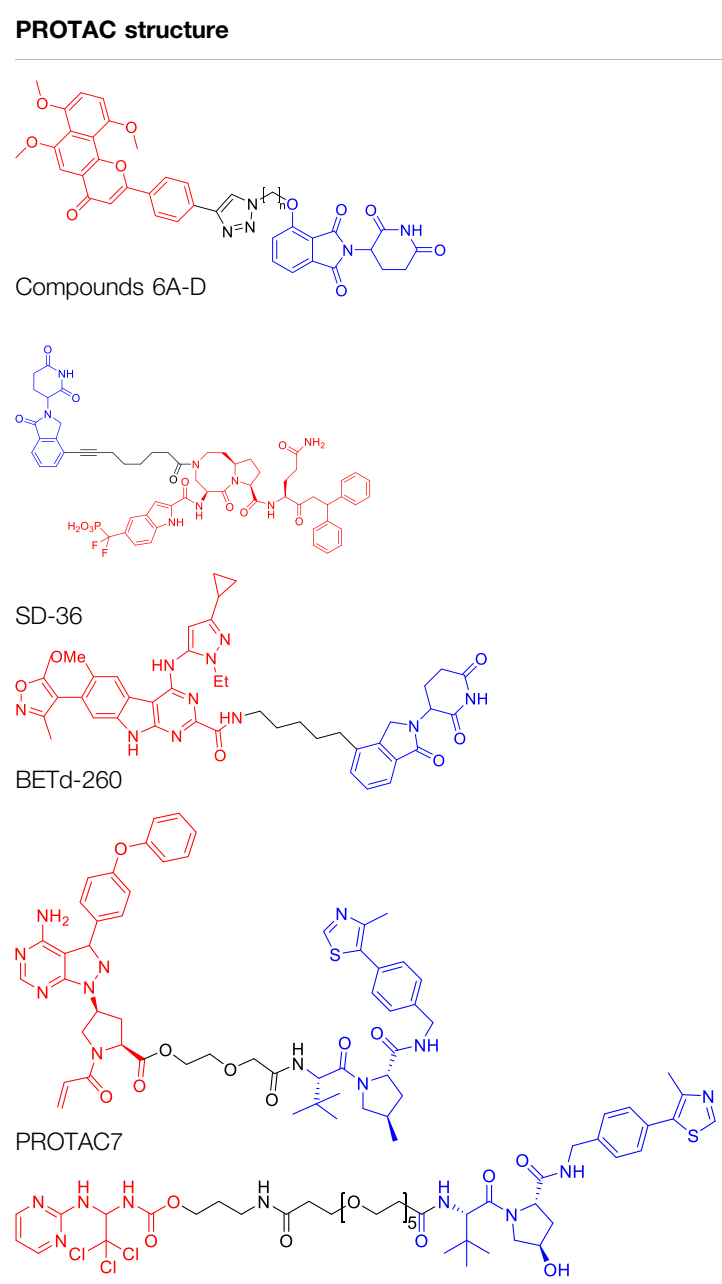

CP5V

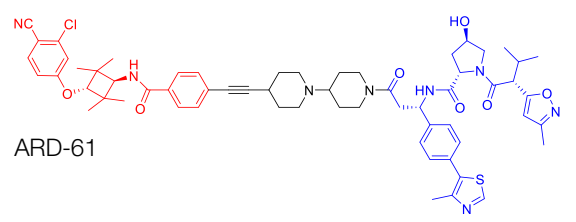
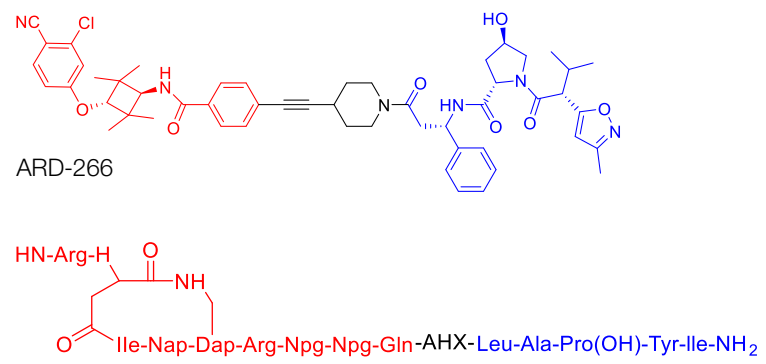

Compound I-6

\section{Target}

CYP1B1
E3 ligase

CRBN
$I_{50}(\mathrm{nM})$

$-$
$E_{50}(n M)$

$-$

STAT3

BET

CRBN

BTK

BLK

Cdc20

AR

AR

ERa
VHL

$\begin{array}{lllll}\mathrm{VHL} & - & - & & 136\end{array}$ Wang et al. (2019b)

$\mathrm{VHL}$

$-$

220

Wang et al. (2019b)

VHL

2

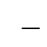

7.2

Han et al. (2019)

$\mathrm{VHL}$

2

$-$

0.5

Han et al. (2019)

9,700
- $\quad$ Dai et al. (2020)

(Continued on following page) 
TABLE 1 | (Continued) Representative small-molecule PROTACs under development.

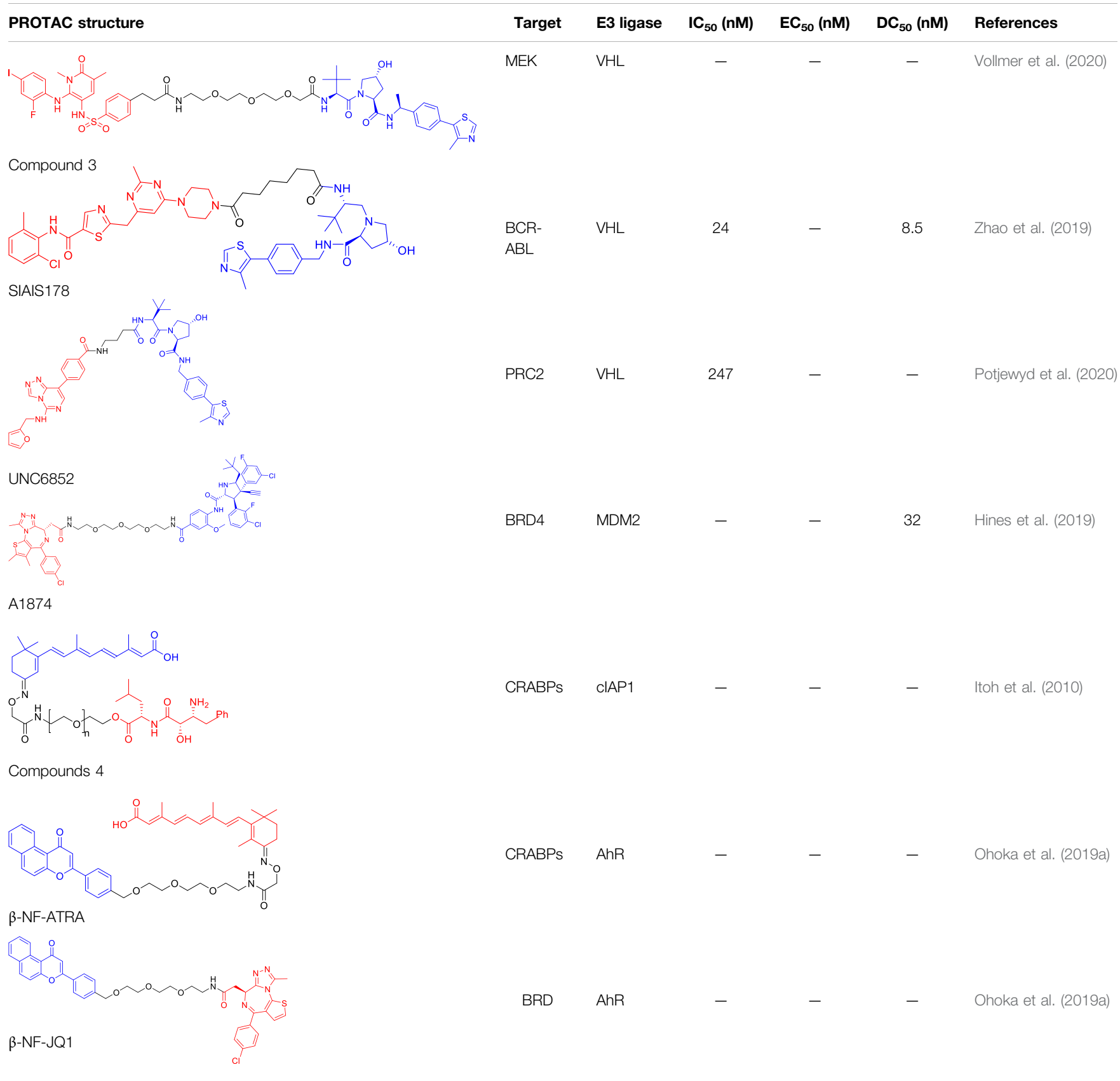

\section{DESIGN AND DEVELOPMENT OF PROTEOLYSIS TARGETING CHIMERICS}

The concept of PROTAC was developed by Crews and Deshaies groups in 2001, and then it has been successfully applied to multiple targets with different subcellular localization, especially in the hijacking of cancer-related kinases (Sakamoto et al., 2001; Sakamoto et al., 2003). The team first proposed a peptide-based PROTAC-1, wherein the ligand ovalbumin binds to the target protein methionine aminopeptidase-2 (MetAP-2), while the IкB, a phosphopeptide (DRHDPSGLDSM) is responsible for recruiting $\mathrm{SCF}^{\beta-T r C P}$ E3 ligase to ubiquitinate MetAP-2, leading to its degradation. In addition, the Crews and Deshaies team also verified that MetAP-2 can be degraded by Xenopus extract through the endogenous ubiquitinproteasome pathway (Sakamoto et al., 2001). This research has opened the door of PROTAC technology, opened up a new era different from the traditional drug treatment, and paved the way for future science (Sakamoto et al., 2001). 
Although there are more than 600 E3 ligases, only a few E3 ligases can be used to degrade target proteins by present PROTAC technology, including SCF ${ }^{\beta-T r C P}$, VHL (Von HippelLindau), MDM2 (Murine double minute 2), IAPs (inhibitor of apoptosis proteins), and CRBN (cereblon) (Zhao et al., 2019). However, with the deepening of research, more and more E3 ligases may be developed in the future to achieve the desired degradation results. In this paper, we classify PROTACs according to E3 ligase and summarize the PROTAC degradation strategies for different target proteins (Table 1).

\section{Cereblon-Based Proteolysis Targeting Chimerics}

CRBN, a component of a cullin-RING ubiquitin ligase (CRL) complex, is the target of thalidomide (Girardini et al., 2019). After binding to CRBN, thalidomide and its analogs inhibit the activity of CRL4 ${ }^{\text {CRBN }}$ E3 ubiquitin ligase in human cells (Fink et al., 2018). BRD4 is a critical protein that is overexpressed in human cancer and promotes the growth and survival of cancer cells (Donati et al., 2018; Zhang F. et al., 2020). In 2015, the Bradner group has developed the first CRBN-based PROTAC, with the structure of pomalidomide capturing CRBN and BRDs inhibitor JQ1 as POI ligand. The resulting compound dBET1 has been shown to induce highly selective CRBN-dependent BET protein degradation in vitro and in vivo and delay the progression of leukemia in mice. They have demonstrated the high efficiency and specificity of ABET1 in degrading BRD family members, such as BRD2, BRD3, and BRD4, by using large-scale proteomic methods (Winter et al., 2015).

TGF- $\beta 1$ is a pleiotropic cytokine and plays an important role in tumor progression (e.g., colorectal and prostate cancer). Also, it is one of the key factors of tumor cell immune escape (Sun D.-Y. et al., 2019; Dai et al., 2019). Feng's team has developed a CRBNbased PROTAC DT- 6 to degrade TGF- $\beta 1$. The TGF- $\beta 1$ ligand is derived from its direct inhibitor P144, and CRBN is recruited by the widely used ligand thalidomide. It has been shown that DT-6 can effectively degrade TGF- $\beta 1$ in cells and reduce its secretion, which is of great significance for diseases that are correlated with the TGF- $\beta 1$ signaling (Feng et al., 2020).

In light of the large effect of structure on degradation efficacy, Su's team has designed a series of PROTACs with varying CDK6 targeting ligands, E3 ligases, and linkers. Considering that the terminal ligands of E3 ligase can also deeply affect the interaction angle between the target protein and the ligase, they have introduced flexible and rigid groups such as alkyl and alkyne into the ligand pomalidomide. To predict which ligase matches CDK6, they have also designed nutlin-3b, VH032, and Bestatin to recruit the E3 ligases MDM2, VHL, and cIAP, respectively. Three FDA-approved CDK4/6 inhibitors (palbociclib, ribociclib, and abemaciclib) have been selected as the binding ligands of the target protein CDK6, which have a strong binding ability to CDK6 with different terminal directions. Finally, it has been found that only CRBN-based PROTAC can degrade CDK6. PROTACs with shorter linkers have shown a higher capacity in CDK6 degradation, suggesting that these shorter molecules have better CRBN recruitment ability on CDK6 (Su et al., 2019).
There are many PROTACs that have been designed with pomalidomide as the CRBN ligand to degrade various POIs, such as MCL-1/BCL-2, BCL-xL, HDAC6, and BTK (Myeku et al., 2016; Sun et al., 2018; Wang X. et al., 2019; Chi et al., 2019; Yang et al., 2019; Xue et al., 2020). Protein-protein interaction (PPI) is involved in most cell processes, including cell differentiation, apoptosis, signal transduction, and transcription (Ryan and Matthews, 2005). Therefore, the role of PPI should not be underestimated, and it has been believed that the target of PPI is the next breakthrough point in disease treatment. Ye's team has used two different BCL-2/MCL-1 inhibitors S1-6 and Nap-1 to develop two different series of PROTACs, C3 and C5 (Wang X. et al., 2019). These PROTACs have shown strong ability in PPI target degradation with $\mathrm{DC}_{50}$ (The $50 \%$ of maximum degradation) of 0.7 and $3.0 \mu \mathrm{M}$, respectively. This study has verified that PROTACs can extend the "target space" to the PPI target. It provides a selective chemical intervention for BCL-2 family protein in chemical biology research and drug discovery.

BTK, a non-receptor cytoplasmic tyrosine kinase, is involved in $B$ cell receptor (BCR) signaling pathway and plays a key role in B cell lymphoma, so its degradation is particularly important (Hendriks et al., 2014). There are many reports on the degradation of BTK by PROTAC. Using CRBN as the E3 ligase, Crews's team has found that MT802 can effectively degrade BTK. It has excellent degradation characteristics in vitro but shows a high clearance rate and short half-life in vivo. They have further replaced the CRBN ligand with the VHL ligand. Unfortunately, the resulting compound have shown low degradation efficiency. Finally, the structure modification of the $\mathrm{CRBN}$ ligand has led to the identification of SJF620, with improved druggability compared with MT802 (Jaime-Figueroa et al., 2020).

Multiple E3 ubiquitin ligases have been selected to degrade the target proteins. Ibrutinib and PLS-123, two covalent inhibitors of BTK, have been chosen as the binding part of BTK due to the high affinity and different folding structures. CRBN and VHL have been selected as the E3 ligase, which were recruited by pomalidomide and $\mathrm{VH} 032$, respectively. Once irreversibly combined with target kinase, an excellent degradation efficiency has been observed in living cells (Xue et al., 2020). Different from Pan's team, CRBN and MDM2 have been selected as the E3 ligases in Rao's study (Sun et al., 2018; Xue et al., 2020). In addition to the recruitment of CRBN by pomalidomide, RG-7112 has been designed as the ligand for MDM2 recruitment and ibrutinib and spebrutinib have been selected as the BTK ligands. It has been found that $\mathrm{CRBN}$ is generally more effective as E3 ligase than MDM2 (Sun et al., 2018). Besides BTK, CRBN- and VHLPROTAC can also effectively degrade EGFR, BRD4, PLK1, and CDK2 (Zhou F. et al., 2020; Zhang H. et al., 2020; Mu et al., 2020).

In addition, $\mathrm{Li}$ et al. have developed a PROTAC that can degrade the cell cycle kinase Weel and provided a new direction for targeted cancer therapy (Jaeger and Winter, 2020; Li et al., 2020). Winzker et al. have described that PDE $\delta$-based PROTACs can effectively and selectively reduce the level of phosphodiesterase- $\delta$ (PDE $\delta$ ) in cells (Winzker et al., 2020). At the same time, it has also increased the expression of various lipid-related enzymes and the level of cholesterol precursor. The results have also shown that $\mathrm{PDE} \delta$ plays a role in the regulation of 
TABLE 2 | PROTACs in clinical stage.

\begin{tabular}{|c|c|c|c|c|c|c|}
\hline Drug & NCT numbers & Target & Lead indication & Phase & Toxicity profile & Preliminary efficacy data \\
\hline $\begin{array}{l}\text { ARV- } \\
110\end{array}$ & NCT03888612 & $\begin{array}{l}\text { Androgen } \\
\text { receptor }\end{array}$ & Prostate cancer & $\begin{array}{l}\text { Phase } \\
2\end{array}$ & $\begin{array}{l}\text { ARV-110 has an acceptable safety profile; } \\
\text { however, co-administration of rosuvastatin } \\
\text { with ARV-110 could produce toxic side } \\
\text { effects. }\end{array}$ & $\begin{array}{l}\text { Two of } 15 \text { patients had a PSA reduction of } \\
\text { more than } 50 \% \text { ( } 140 \text { mg dose group); two of } \\
\text { five patients ( } 40 \% \text { ) with T878 or H } 875 \\
\text { mutations in AR had PSA reductions over } \\
50 \% \text {; two of } 15 \text { patients ( } 13 \% \text { ) with wild-type } \\
\text { AR also had PSA reductions over } 50 \%\end{array}$ \\
\hline $\begin{array}{l}\text { ARV- } \\
471\end{array}$ & NCT04072952 & $\begin{array}{l}\text { Oestrogen } \\
\text { receptor }\end{array}$ & Breast cancer & $\begin{array}{l}\text { Phase } \\
2\end{array}$ & $\begin{array}{l}\text { ARV- } 471 \text { is well tolerated at all tested dose } \\
\text { levels; no treatment-related grade } 3 \text { of } 4 \\
\text { adverse events, and DLTs were reported. The } \\
\text { most common treatment-related grade } 1-2 \\
\text { adverse events are nausea ( } 24 \%) \text {, arthralgia } \\
\text { (19\%), fatigue (19\%), and decreased } \\
\text { appetite (14\%) }\end{array}$ & $\begin{array}{l}\text { One patient (totally } 21 \text { adult patients) in ARV- } \\
471 \text { trial had a } 51 \% \text { reduction in target lesion } \\
\text { size (confirmed PR), two patients had } \\
\text { unconfirmed PRs, and one additional patient } \\
\text { showed stable disease, with a target lesion } \\
\text { reduction of more than } 50 \% \text {; five of } 12 \\
\text { patients ( } 42 \% \text { ) achieved CBR }\end{array}$ \\
\hline $\begin{array}{l}\text { KT- } \\
474\end{array}$ & NCT04772885 & IRAK4 & $\begin{array}{l}\text { Autoimmune } \\
\text { including } A D, H S \\
\text { and RA }\end{array}$ & $\begin{array}{l}\text { Phase } \\
1\end{array}$ & NR & NR \\
\hline $\begin{array}{l}\text { NX- } \\
2127\end{array}$ & NCT04830137 & BTK & B cell malignancies & $\begin{array}{l}\text { Phase } \\
1\end{array}$ & NR & NR \\
\hline
\end{tabular}

NR, not reported yet (Recruiting Status).

sterol synthesis (Winzker et al., 2020). Signal transducer and activator of transcription 3 (STAT3) activation is beneficial to the survival, reproduction, metastasis, and immune escape of tumor cells (Furtek et al., 2016). STAT3 is closely related to the adverse prognosis of human cancer and has become a promising therapeutic target for cancer and other diseases. Zhou et al. have developed SD-36 as a highly selective and potent PROTAC degrader of STAT3. SD-36 can inhibit the growth of leukemia and lymphoma cell lines with highly phosphorylated STAT3 at low nanomolar concentrations in vitro. SD-36 can also completely and persistently regress the tumor growth in mice bearing the Molm-16 xenografts. SD-36 has been found to rapidly induce the degradation of STAT3 but has no significant effect on other STAT isoforms (Zhou et al., 2019).

Bromodomain and Extra-Terminal domain (BET) family proteins are epigenetic regulatory factors related to the expression of multiple oncogenes (Stathis and Bertoni, 2018). BETd-260 is an effective PROTAC degradation agent synthesized on the basis of BET SMIs. The in vivo and in vitro experiments have shown that it can induce a large amount of apoptosis in osteosarcoma (OS) cells and OS xenograft tumor tissues and ultimately lead to the depth and sustained inhibition of tumor growth in both mouse OS cell line-derived xenograft and patientderived xenograft (PDX) models (Shi et al., 2019).

\section{Von Hippel-Lindau-Based Proteolysis Targeting Chimerics}

VHL, an important tumor suppressor of clear cell renal cell carcinoma (ccRCC), is a part of the E3 ubiquitin ligase complex (Zhang et al., 2018). Its regulatory pathway involves the activity of E3 ligase, which can target hypoxia inducible factors $\alpha$ (including HIF1 $\alpha$ and HIF2 $\alpha$ ) for proteasomal degradation (Pezzuto and Carico, 2018). Recent studies have shown that VHL possesses additional HIF-independent functions. For example, in VHL-deficient ccRCC, the assembly of VHL-mediated intercellular junctions is achieved through HIFindependent mechanisms (Calzada et al., 2006; Zhang and Zhang, 2018). Accordingly, there are many PROTACs that use VHL as the E3 ubiquitin ligase to degrade the target protein.

Kim's team has also recruited CRBN and VHL by using pomalidomide and VH032, respectively (Kim et al., 2019). They are dedicated to knowing whether the E3 ligase itself can be ubiquitinated and degraded by another E3 ligase when two different $\mathrm{E} 3$ ligases are put together. Therefore, they have designed PROTACs to target CRBN or VHL itself. However, in all cases, the results have shown that the level of CRBN is decreased while the level of VHL is unchanged or increased, indicating that RPOTAC can ubiquitously degrade CRBN itself (Kim et al., 2019).

Chronic myeloid leukemia (CML) is a kind of malignant tumor that affects blood and bone marrow. It is characterized by the production of a large number of immature leukocytes to inhibit the normal hematopoiesis of bone marrow. BCR-ABL1 is a critical kinase in CML, which drives the over production and expansion of white blood cells in bone marrow and finally squeezes out normal cells in the bone marrow (Burslem et al., 2019). Crews lab has developed a series of PROTACs for BCR-ABL1 protein. They have used their previously developed E3 ligase VHL ligand to degrade the fusion protein (Buckley et al., 2012a; Buckley et al., 2012b). Their research further proves the great ability of the PROTAC technique, for it is not only a potential therapeutic method but also a tool to explore basic biology (Burslem et al., 2019).

Mitosis is the primary mechanism of cell proliferation, and thus inhibition of cancer proliferation can be achieved by blocking the process of mitosis. Cell division cycle 20 (Cdc20) is a key factor in mitosis, and targeting $\mathrm{Cdc} 20$ has been considered as a novel cancer therapeutic strategy (Wang et al., 2015). A PROTAC molecule named CP5V has been designed to induce the degradation of Cdc20, with PEG5 being used to connect the Cdc20 ligand and the VHL ligand. CP5V can effectively degrade 
Cdc20 and eventually overcome cell division slippage, which is the main reason for drug resistance of taxane in breast cancer treatment (Chi et al., 2019).

Overexpression of anti-apoptotic proteins such as BCL-2 and BCL-XL will promote the development and progression of cancer (Singh et al., 2019). Many SMIs targeting the BCL-2 family have been developed, such as ABT263 (a BCL-2 and BCL-xL dual inhibitor) and ABT199 (a BCL-2 selective inhibitor) (Chang et al., 2016; Naqvi et al., 2017). However, ABT263 has the obvious disadvantages of on-target toxicity and dose-limiting thrombocytopenia, which greatly limits its clinical application. Although ABT199 has become the only BCL-2 family anticancer drug approved by the FDA, it cannot be used in the treatment of solid tumors because most solid tumor cells do not rely on BCL-2 expression. The shortcomings of traditional inhibitors prompted Khan's team to develop a PROTAC, DT2216, which can target BCL-xL protein degradation by the VHL E3 ligase (Khan et al., 2019). Compared with ABT263 (BCL-xL inhibitor), DT2216 not only has strong inhibitory effects on all kinds of BCL-xL -dependent leukemia and cancer cells in vitro but also has much less toxicity to platelets because of the poor expression of VHL in platelets. DT2216, either as a single drug or combined with other chemotherapeutic drugs, can effectively inhibit the tumor growth in several xenograft mouse models without causing significant thrombocytopenia in vivo. Their research has shown that DT2216 may have a great potential to replace the traditional SMIs as a safe and effective anticancer drug targeting the BCL-2 family (Khan et al., 2019).

Androgen receptor (AR) antagonists play a pivotal role in the treatment of metastatic castration-resistant prostate cancer (mCRPC), but they still face the problem of drug resistance. Using PROTAC technology, Han et al. have developed several AR degraders by using four different $A R$ antagonists as the $A R$ ligands, of which ARD-61 with ARI-16 as the AR ligand is the most effective one (Han et al., 2019). Compared with AR antagonists, ARD-61 has a better inhibitory effect on cancer cell proliferation and can overcome drug resistance, suggesting that PROTAC-mediated degradation of AR has great clinical potential. In addition, the team has also proved that even if the E3 ligands have a micromolar binding affinity to ubiquitin ligase E3, the obtained PROTAC products can still effectively degrade the target protein, which contributes to overwhelming the difficulty of seeking high active ligands for E3 ligands complex (Han et al., 2019).

It has been reported that polycomb repressive complex 2 (PRC2) is both a carcinogenic gene and a tumor suppressor gene (Gan et al., 2018). The catalytic activity of PRC2 depends on the embryonic ectodermal development (EED), enhancer of zeste homolog (EZH1) or EZH2, and suppressor of zeste homolog 12 (SUZ12) (Margueron and Reinberg, 2011). PRC2 is located at histone 3 lysine 27 (H3K27), and $\mathrm{H} 3 \mathrm{~K} 27$ trimethylation (H3K27me3) is the key mechanism for transcriptional repression (Ferrari et al., 2014). EZH2 is up-regulated in a variety of cancer types, such as breast, colorectal, and prostate cancer. The overexpression of EZH2 and the increase in the $\mathrm{H} 3 \mathrm{~K} 27 \mathrm{me} 3$ level contribute to cancer cell proliferation and chemotherapy resistance, leading to a low survival rate in clinical practice. EED, EZH2, and SUZ12 are also susceptible to cancer mutations. Therefore, targeting EED and EZH2 can effectively block the catalytic activity of PRC2. UNC6852 is a PROTAC designed using the EED ligand EED226. It has been shown that UNC6852 has time- and concentration-dependent inhibitory effects on EED, EZH2, and SUZ12 of PRC2 in HeLa cells in a VHL-dependent manner, with a reduced level of H3K27me3 (Potjewyd et al., 2020).

\section{Murine Double Minute 22-Based Proteolysis Targeting Chimerics}

P53 is an indispensable tumor suppressor that regulates cell cycle, apoptosis, DNA damage repair, and other processes (Qin J.-J. et al., 2017; Qin et al., 2018). MDM2 is one of the main inhibitors of p53; it can bind to $\mathrm{p} 53$ through its $\mathrm{N}$-terminal domain (region I) to form the MDM2-p53 complex and reduce the activity and level of p53 (Hou et al., 2019; Wang et al., 2020a). MDM2 gene exists in the cell genome of human malignant tumors such as lung and colon cancer (Mendoza et al., 2014). Overexpressed MDM2 can be detected in many malignant tumors, so MDM2 has become an effective target for the development of anticancer drugs (Nag et al., 2013). With the emergence of PROTAC, MDM2 has also been developed as an E3 ligase to degrade AR (Sun X. et al., 2019) and BRD4 (Groppe, 2019). Nutlin-3a and Idasanutlin are usually selected as the E3 ligase ligands. Although nutlin-3a specifically binds to MDM2 with a high binding affinity, there are few PROTACs that are designed and developed based on nutlin-3a. A1874, a BRD4 PROTAC based on nutlin-3a, degraded $98 \%$ of its target protein at nanomolar concentrations and activated the p53 signaling pathway. This study has also shown that for the same target protein (e.g., BRD4), MDM2-based PROTAC has a better degrading effect than CRBN-based PROTAC (provided that in the context of wild-type p53) (Hines et al., 2019).

\section{Inhibitor of Apoptosis Proteins-Based Proteolysis Targeting Chimerics}

Available data have confirmed that IAPs are involved in cancer and other human diseases and have been considered as a potential target for cancer treatment (LaCasse et al., 2008). Mammalian IAP protein family includes at least 8 members, among which cIAP1 and cIAP2 function as E3 ubiquitin ligases to mediate the ubiquitination of target proteins (Fulda, 2017). In 2010, Hashimoto's team has hijacked cIAP1-E3 ligase using bestatinmethyl ester MeBS and used all-trans retinoic acid (ATRA) as a warhead to develop the first cIAP1-based PROTAC (compounds 4) to degrade cellular retinoic acid binding protein (CRABP-I/-II) (Itoh et al., 2010). Compounds 4 has been shown to induce the selective loss of CRABP-I and -II proteins in cells in a concentration-dependent manner. With the deepening of research, more and more IAP1-based PROTACs have been developed. Interestingly, unlike other PROTACs, IAP-based PROTACs have dual functions of degradation of POI and IAP, which is beneficial to the anti-tumor function and also suggests that it should be careful in design to avoid unexpected side effects (Ohoka et al., 2019b; Liu et al., 2020). 


\section{CLINICAL RESEARCH ON PROTEOLYSIS TARGETING CHIMERICS}

Currently, several PROTACs have entered clinical trials (Table 2), and some of them have shown encouraging results, such as ARV-110 and ARV-471. ARV-110, an oral protein degradation agent, binds AR specifically and mediates its degradation (Neklesa et al., 2018). ARV-110 completely degraded $\mathrm{AR}\left(\mathrm{DC}_{50}<1 \mathrm{nM}\right)$ in all tested cell lines (Neklesa et al., 2019) and Oral ARV-110 (10 mg/kg) significantly inhibited the growth of enzalutamide-insensitive tumors in the PDX model (Wang et al., 2020b). ARV-110 degrades clinically relevant mutant AR proteins and retains activity in a hyperandrogen environment. The early reported data (by January 2020) from the first-in-human, phase I study of ARV-110 demonstrated its safety and tolerability in patients with metastatic castrateresistant prostate cancer (mCRPC) (Petrylak et al., 2020). ARV-110 was administered to 18 patients at four doses, including $35 \mathrm{mg}(N=3), 70 \mathrm{mg}(N=4), 140 \mathrm{mg}(N=8)$ and $280 \mathrm{mg}(N=3)$. Among them, 12 patients received ARV-110 combined with enzalutamide (ENZ)/abiraterone (ABI), and 14 patients received prior chemotherapy. One patient administered ARV-110 280 mg experienced Grade (GR) 4 elevated AST/ALT followed by an acute renal failure while taking together with rosuvastatin (ROS). Similarly, another patient developed GR3 AST/ALT while taking ROS. Their plasma concentrations of ROS were increased accompanied by AST/ALT elevations, suggesting that concurrent ROS could produce toxic side effects. For other patients, no related GR 3/4 adverse events were reported. Generally, ARV-110 possesses an acceptable safety profile. 15 of 18 patients were evaluable for prostate specific antigen (PSA) response. Of these, two patients had a PSA reduction of more than $50 \%$ ( $140 \mathrm{mg}$ dose group), and both of them received prior therapy including ENZ and ABI, chemotherapy, bicalutamide, radium-223 and others.

According to the recent interim clinical data released by Arvinas (https://ir.arvinas.com/), in the phase 1 clinical trial, ARV-110 shows promising activity in a very late-line mCRPC patients, with PSA reductions over 50\% at doses greater than $280 \mathrm{mg}$. Previous studies have shown that multiple pretreatments will lead to tumor resistance to targeted AR therapy, and improve the heterogeneity of tumor, resulting in a decreased efficacy of AR targeted therapy. Molecular biological analysis of patients treated with ARV-110 showed that $84 \%$ of patients carried non-AR gene mutations. Among the highly heterogeneous phase 1 patients, Arvinas has identified an advanced population with a molecular definition that has a particularly strong response to ARV-110. Of the five patients with T878 or H875 mutations in AR, two (40\%) had a PSA reduction of more than $50 \%$, including one with PR confirmed by RECIST and tumor size reduction of $80 \%$. Additionally, two of 15 patients (13\%) with wild-type AR also had PSA reductions over $50 \%$. These results suggest ARV-110 has great potentials in molecularly defined population (T878/H875) and in wild-type patients.

ARV-471 is an estrogen receptor (ER) alpha PROTAC molecule that degrades ER in ER-positive breast cancer cell lines with $\mathrm{DC}_{50}$ around $1 \mathrm{nM}$. It can decrease the expression of classically regulated ER-target genes and suppress the growth of ER-dependent cell lines (including cell lines expressing ESR1 variants such as Y537S and D538G) via degradation of ER. Oral administration of single agent ARV-471 (3, 10, and $30 \mathrm{mpk} /$ day) shows significant anti-tumor activity in estradiol-dependent MCF7 xenografts along with ER protein reductions of over 90\%. Excitingly, more pronounced tumor growth inhibition is observed $(131 \%$ TGI) in the MCF7 xenograft model, accompanied by significant reductions in ER protein levels when combined with a CDK4/6 inhibitor palbociclib. Furthermore, the combination of ARV-471 and CDK4/6 inhibitor palbociclib showed great superiority over the combination of fulvestrant with palbociclib in tumor regressions. Also, ARV-471 (10 mpk) completely inhibited growth and markedly reduced mutant ER protein levels in ESR1 mutant hormone-independent PDX model (Flanagan et al., 2019). These promising results translate well into clinical trials. Recently, Arvinas has also announced ARV-471 for the treatment of locally advanced or metastatic ER-positive/ HER2-negative breast cancer, and its phase I clinical trials have started in the second half of 2019 (https://ir.arvinas.com/). Analysis of the mid-term trial showed that ARV-471 could significantly reduce ER expression level in tumor tissues, with an average of $62 \%$ and a maximum of $90 \%$. Moreover, ARV-471 could degrade both wild-type ER and mutant ER. According to the RECIST evaluation, one patient (a total of 21 adult patients) in the ARV-471 trial had a 51\% reduction in target lesion size (confirmed PR), two patients had unconfirmed PRs, and one additional patient showed stable disease, with a target lesion reduction of more than $50 \%$. In the clinical benefit rate (CBR) evaluation, five of the 12 patients (42\%) achieved CBR (defined as PRS + complete response + stable disease at 6 months).

\section{CONCLUSION AND PERSPECTIVES}

Different from the traditional SMIs, PROTAC is a new strategy of inducing the ubiquitination degradation of target proteins. However, it is worth noting that up to now, less than 10 of more than $600 \mathrm{E} 3$ ubiquitin ligases have been used to degrade target proteins, which reminds scholars to expand their knowledge in this area.

Although the PROTAC technology has made remarkable achievements since its development in 2001, there are still some problems in the process of design and application of PROTAC. For example, the effectiveness of PROTAC depends not only on the ligands of POIs and E3 ligases but also on the length and chemical properties of the linkers connecting the ligands. In addition, the binding strength of ligands, spatial orientation, cell permeability, and other factors will have important impacts on the efficacy of PROTACs. Therefore, how these factors work together to achieve the highest efficiency is a major scientific problem to be addressed. Although the PROTACs can target protein for degradation, it cannot actively locate at the target tumor tissue and may have the off-target effects. Therefore, the safety is another challenge for 
PROTACs that should be taken into account. Considering the different expression of E3 ligase at different time and in different tissues, high selectivity can be achieved through tissue-specific E3 protein. After the completion of the theoretical design, several rounds of experiments are needed to optimize the structures of PROTACs and finally locate the ligands of the POIs and the E3 ligases into an appropriate spatial structure to form ternary degradation complex. It takes much time and manpower, so the application of new design strategies or technologies (e.g., CADD and $\mathrm{AI}$ ) has a huge importance in rational design of PROTACs.

One of the biggest advantages of PROTAC technology is its great potential to target "undruggable" proteins. Because small molecule ligands can well bind to the target proteins, most of the successful PROTACs currently use SMIs as ligands to target druggable proteins. Additionally, studies by ARV-471 have clearly shown that PROTAC could produce a synergistic effect on tumor inhibition when combined with kinase inhibitors including $\mathrm{CDK} 4 / 6$ inhibitors. It suggests that combination of PROTAC either with targeted inhibitors or with chemotherapy/antibody drugs may represent a good alternative strategy for cancer therapy. It is believed that it will open up a broad road for the development of PROTAC technology and the discovery of new anticancer drugs once these problems mentioned above are solved.

\section{REFERENCES}

Buckley, D. L., Gustafson, J. L., Van Molle, I., Roth, A. G., Tae, H. S., Gareiss, P. C., et al. (2012a). Small-Molecule Inhibitors of the Interaction between the E3 Ligase VHL and HIF1a. Angew. Chem. Int. Ed. 51, 11463-11467. doi:10.1002/ anie. 201206231

Buckley, D. L., Van Molle, I., Gareiss, P. C., Tae, H. S., Michel, J., Noblin, D. J., et al. (2012b). Targeting the von Hippel-Lindau E3 Ubiquitin Ligase Using Small Molecules To Disrupt the VHL/HIF-1a Interaction. J. Am. Chem. Soc. 134, 4465-4468. doi:10.1021/ja209924v

Buckley, D. L., Raina, K., Darricarrere, N., Hines, J., Gustafson, J. L., Smith, I. E., et al. (2015). HaloPROTACS: Use of Small Molecule PROTACs to Induce Degradation of HaloTag Fusion Proteins. ACS Chem. Biol. 10, 1831-1837. doi:10.1021/acschembio.5b00442

Burslem, G. M., Schultz, A. R., Bondeson, D. P., Eide, C. A., Savage Stevens, S. L., Druker, B. J., et al. (2019). Targeting BCR-ABL1 in Chronic Myeloid Leukemia by PROTAC-Mediated Targeted Protein Degradation. Cancer Res. 79, 4744-4753. doi:10.1158/0008-5472.can19-1236

Calzada, M. J., Esteban, M. A., Feijoo-Cuaresma, M., Castellanos, M. C., NaranjoSuárez, S., Temes, E., et al. (2006). von Hippel-Lindau tumor suppressor protein regulates the assembly of intercellular junctions in renal cancer cells through hypoxia-inducible factor-independent mechanisms. Cancer Res. 66, 1553-1560. doi:10.1158/0008-5472.can-05-3236

Chang, J., Wang, Y., Shao, L., Laberge, R.-M., Demaria, M., Campisi, J., et al. (2016). Clearance of Senescent Cells by ABT263 Rejuvenates Aged Hematopoietic Stem Cells in Mice. Nat. Med. 22, 78-83. doi:10.1038/nm. 4010

Chi, J., Li, H., Zhou, Z., Izquierdo-Ferrer, J., Xue, Y., Wavelet, C. M., et al. (2019). A Novel Strategy to Block Mitotic Progression for Targeted Therapy. EBioMedicine. 49, 40-54. doi:10.1016/j.ebiom.2019.10.013

Coats, S., Williams, M., Kebble, B., Dixit, R., Tseng, L., Yao, N.-S., et al. (2019). Antibody-Drug Conjugates: Future Directions in Clinical and Translational Strategies to Improve the Therapeutic Index. Clin. Cancer Res. 25, 5441-5448. doi:10.1158/1078-0432.ccr-19-0272

\section{AUTHOR CONTRIBUTIONS}

J-JQ, X-DC, and W-DZ conceptualized the manuscript. S-MQ, JD, Z-YX, X-DC, W-DZ, and J-JQ collected the literature, wrote the manuscript, and made the figures. J-JQ edited and made significant revisions to the manuscript. All authors read and approved the final manuscript.

\section{FUNDING}

This work was supported by grants from Zhejiang Provincial Natural Science Foundation of China (LQ21B020003, LR21H280001), Program of Zhejiang Provincial TCM Sci-tech Plan (2020ZZ005), and National Natural Science Foundation of China (81903842).

\section{ACKNOWLEDGMENTS}

We thank the current and former members of our laboratories and collaborators for their contributions to the publications cited in this review article. The research field in PROTAC is rapidly growing, and we apologize for not being able to cite all the recent publications, due to space limitation.

Cyrus, K., Wehenkel, M., Choi, E.-Y., Han, H.-J., Lee, H., Swanson, H., et al. (2011). Impact of Linker Length on the Activity of PROTACs. Mol. Biosyst. 7, 359-364. doi: $10.1039 / \mathrm{c} 0 \mathrm{mb} 00074 \mathrm{~d}$

Dai, G., Sun, B., Gong, T., Pan, Z., Meng, Q., and Ju, W. (2019). Ginsenoside Rb2 Inhibits Epithelial-Mesenchymal Transition of Colorectal Cancer Cells by Suppressing TGF- $\beta /$ Smad Signaling. Phytomedicine. 56, 126-135. doi:10. 1016/j.phymed.2018.10.025

Dai, Y., Yue, N., Gong, J., Liu, C., Li, Q., Zhou, J., et al. (2020). Development of CellPermeable Peptide-Based PROTACs Targeting Estrogen Receptor a. Eur. J. Med. Chem. 187, 111967. doi:10.1016/j.ejmech.2019.111967

Donati, B., Lorenzini, E., and Ciarrocchi, A. (2018). BRD4 and Cancer: Going beyond Transcriptional Regulation. Mol. Cancer. 17, 164. doi:10.1186/s12943018-0915-9

Dong, J., Qin, Z., Zhang, W.-D., Cheng, G., Yehuda, A. G., Ashby, C. R., Jr., et al. (2020). Medicinal Chemistry Strategies to Discover P-Glycoprotein Inhibitors: An Update. Drug Resist. Updates. 49, 100681. doi:10.1016/j. drup.2020.100681

Dong, J., Zhang, Q., Wang, Z., Huang, G., and Li, S. (2018). Recent Advances in the Development of Indazole-Based Anticancer Agents. ChemMedChem. 13, 1490-1507. doi:10.1002/cmdc.201800253

Feng, Y., Su, H., Li, Y., Luo, C., Xu, H., Wang, Y., et al. (2020). Degradation of Intracellular TGF-B1 by PROTACs Efficiently Reverses M2 Macrophage Induced Malignant Pathological Events. Chem. Commun. 56, 2881-2884. doi:10.1039/c9cc08391j

Ferrari, K. J., Scelfo, A., Jammula, S., Cuomo, A., Barozzi, I., Stützer, A., et al. (2014). Polycomb-dependent H3K27me1 and H3K27me2 Regulate Active Transcription and Enhancer Fidelity. Mol. Cel. 53, 49-62. doi:10.1016/j. molcel.2013.10.030

Fink, E. C., Mcconkey, M., Adams, D. N., Haldar, S. D., Kennedy, J. A., Guirguis, A. A., et al. (2018). Crbn I391V Is Sufficient to Confer In Vivo Sensitivity to Thalidomide and its Derivatives in Mice. Blood. 132, 1535-1544. doi:10.1182/ blood-2018-05-852798

Flanagan, J., Qian, Y., Gough, S., Andreoli, M., Bookbinder, M., Cadelina, G., et al. (2019). Abstract P5-04-18: ARV-471, an Oral Estrogen Receptor PROTAC Degrader for Breast Cancer. Cancer Res. 79, P5-P04-18. doi:10.1158/15387445.SABCS18-P5-04-18 
Fulda, S. (2017). Smac Mimetics to Therapeutically Target IAP Proteins in Cancer. Int. Rev. Cel Mol Biol. 330, 157-169. doi:10.1016/bs.ircmb.2016.09.004

Furtek, S. L., Backos, D. S., Matheson, C. J., and Reigan, P. (2016). Strategies and Approaches of Targeting STAT3 for Cancer Treatment. ACS Chem. Biol. 11, 308-318. doi:10.1021/acschembio.5b00945

Gan, L., Yang, Y., Li, Q., Feng, Y., Liu, T., and Guo, W. (2018). Epigenetic Regulation of Cancer Progression by EZH2: from Biological Insights to Therapeutic Potential. Biomark Res. 6, 10. doi:10.1186/s40364-018$0122-2$

Girardini, M., Maniaci, C., Hughes, S. J., Testa, A., and Ciulli, A. (2019). Cereblon versus VHL: Hijacking E3 Ligases against Each Other Using PROTACs. Bioorg. Med. Chem. 27, 2466-2479. doi:10.1016/j.bmc.2019.02.048

Groppe, J. C. (2019). Induced Degradation of Protein Kinases by Bifunctional Small Molecules: a Next-Generation Strategy. Expert Opin. Drug Discov. 14, 1237-1253. doi:10.1080/17460441.2019.1660641

Guo, J., Liu, J., and Wei, W. (2019). Degrading Proteins in Animals: "PROTAC"tion Goes In Vivo. Cell Res. 29, 179-180. doi:10.1038/s41422019-0144-9

Han, X., Zhao, L., Xiang, W., Qin, C., Miao, B., Xu, T., et al. (2019). Discovery of Highly Potent and Efficient PROTAC Degraders of Androgen Receptor (AR) by Employing Weak Binding Affinity VHL E3 Ligase Ligands. J. Med. Chem. 62, 11218-11231. doi:10.1021/acs.jmedchem.9b01393

Hendriks, R. W., Yuvaraj, S., and Kil, L. P. (2014). Targeting Bruton's Tyrosine Kinase in B Cell Malignancies. Nat. Rev. Cancer. 14, 219-232. doi:10.1038/ $\operatorname{nrc} 3702$

Hines, J., Lartigue, S., Dong, H., Qian, Y., and Crews, C. M. (2019). MDM2Recruiting PROTAC Offers Superior, Synergistic Antiproliferative Activity via Simultaneous Degradation of BRD4 and Stabilization of P53. Cancer Res. 79, 251-262. doi:10.1158/0008-5472.can-18-2918

Hou, H., Sun, D., and Zhang, X. (2019). The Role of MDM2 Amplification and Overexpression in Therapeutic Resistance of Malignant Tumors. Cancer Cel Int. 19, 216. doi:10.1186/s12935-019-0937-4

Itoh, Y., Ishikawa, M., Naito, M., and Hashimoto, Y. (2010). Protein Knockdown Using Methyl Bestatin-Ligand Hybrid Molecules: Design and Synthesis of Inducers of Ubiquitination-Mediated Degradation of Cellular Retinoic Acid-Binding Proteins. J. Am. Chem. Soc. 132, 5820-5826. doi:10.1021/ja100691p

Jaeger, M. G., and Winter, G. E. (2020). Expanding the Degradable Proteome: Designing PROTACs by the Book. Cel Chem. Biol. 27, 14-16. doi:10.1016/j. chembiol.2019.12.009

Jaime-Figueroa, S., Buhimschi, A. D., Toure, M., Hines, J., and Crews, C. M. (2020). Design, Synthesis and Biological Evaluation of Proteolysis Targeting Chimeras (PROTACs) as a BTK Degraders with Improved Pharmacokinetic Properties. Bioorg. Med. Chem. Lett. 30, 126877. doi:10.1016/j.bmcl.2019. 126877

Khan, S., Zhang, X., Lv, D., Zhang, Q., He, Y., Zhang, P., et al. (2019). A Selective BCL-XL PROTAC Degrader Achieves Safe and Potent Antitumor Activity. Nat. Med. 25, 1938-1947. doi:10.1038/s41591-019-0668-z

Kim, K., Lee, D. H., Park, S., Jo, S. H., Ku, B., Park, S. G., et al. (2019). Disordered Region of Cereblon Is Required for Efficient Degradation by Proteolysis-Targeting Chimera. Sci. Rep. 9, 19654. doi:10.1038/s41598019-56177-5

Kregel, S., Wang, C., Han, X., Xiao, L., Fernandez-Salas, E., Bawa, P., et al. (2020). Androgen Receptor Degraders Overcome Common Resistance Mechanisms Developed during Prostate Cancer Treatment. Neoplasia. 22, 111-119. doi:10. 1016/j.neo.2019.12.003

Lacasse, E. C., Mahoney, D. J., Cheung, H. H., Plenchette, S., Baird, S., and Korneluk, R. G. (2008). IAP-targeted Therapies for Cancer. Oncogene. 27, 6252-6275. doi:10.1038/onc.2008.302

Li, Z., Pinch, B. J., Olson, C. M., Donovan, K. A., Nowak, R. P., Mills, C. E., et al. (2020). Development and Characterization of a Weel Kinase Degrader. Cel Chem. Biol. 27, 57-65. doi:10.1016/j.chembiol.2019.10.013

Liu, J., Ma, J., Liu, Y., Xia, J., Li, Y., Wang, Z. P., et al. (2020). PROTACs: A Novel Strategy for Cancer Therapy. Semin. Cancer Biol. 67, 171-179. doi:10.1016/j. semcancer.2020.02.006

Lu, X., Smaill, J. B., and Ding, K. (2020). New Promise and Opportunities for Allosteric Kinase Inhibitors. Angew. Chem. Int. Ed. 59, 13764-13776. doi:10. 1002/anie.201914525
Mangal, S., Gao, W., Li, T., and Zhou, Q. (2017). Pulmonary Delivery of Nanoparticle Chemotherapy for the Treatment of Lung Cancers: Challenges and Opportunities. Acta Pharmacol. Sin. 38, 782-797. doi:10. 1038/aps.2017.34

Margueron, R., and Reinberg, D. (2011). The Polycomb Complex PRC2 and its Mark in Life. Nature. 469, 343-349. doi:10.1038/nature09784

Mendoza, M., Mandani, G., and Momand, J. (2014). The MDM2 Gene Family. Biomol. Concepts. 5, 9-19. doi:10.1515/bmc-2013-0027

Mu, X., Bai, L., Xu, Y., Wang, J., and Lu, H. (2020). Protein Targeting Chimeric Molecules Specific for Dual Bromodomain 4 (BRD4) and Pololike Kinase 1 (PLK1) Proteins in Acute Myeloid Leukemia Cells. Biochem. Biophysical Res. Commun. 521, 833-839. doi:10.1016/j.bbrc. 2019.11.007

Myeku, N., Clelland, C. L., Emrani, S., Kukushkin, N. V., Yu, W. H., Goldberg, A. L., et al. (2016). Tau-driven 26S Proteasome Impairment and Cognitive Dysfunction Can Be Prevented Early in Disease by Activating cAMP-PKA Signaling. Nat. Med. 22, 46-53. doi:10.1038/nm.4011

Nag, S., Qin, J., Srivenugopal, K. S., Wang, M., and Zhang, R. (2013). The MDM2P53 Pathway Revisited. J. Biomed. Res. 27, 254-271. doi:10.7555/JBR.27. 20130030

Nam, T., Han, J. H., Devkota, S., and Lee, H. W. (2017). Emerging Paradigm of Crosstalk between Autophagy and the Ubiquitin-Proteasome System. Mol. Cell. 40, 897-905. doi:10.14348/molcells.2017.0226

Nandi, D., Tahiliani, P., Kumar, A., and Chandu, D. (2006). The UbiquitinProteasome System. J. Biosci. 31, 137-155. doi:10.1007/bf02705243

Naqvi, K., Konopleva, M., and Ravandi, F. (2017). Targeted Therapies in Acute Myeloid Leukemia: a Focus on FLT-3 Inhibitors and ABT199. Expert Rev. Hematol. 10, 863-874. doi:10.1080/17474086.2017.1366852

Neklesa, T. K., Winkler, J. D., and Crews, C. M. (2017). Targeted Protein Degradation by PROTACs. Pharmacol. Ther. 174, 138-144. doi:10.1016/j. pharmthera.2017.02.027

Neklesa, T., Snyder, L. B., Willard, R. R., Vitale, N., Pizzano, J., Gordon, D. A., et al. (2019). ARV-110: An Oral Androgen Receptor PROTAC Degrader for Prostate Cancer. J. Clin. Oncol. 37, 259. doi:10.1200/jco.2019.37. 7_suppl.259

Neklesa, T., Snyder, L. B., Willard, R. R., Vitale, N., Raina, K., Pizzano, J., et al. (2018). Abstract 5236: ARV-110: An Androgen Receptor PROTAC Degrader for Prostate Cancer. Cancer Res. 78, 5236. doi:10.1158/1538-7445.AM20185236

Ohashi, K., Maruvka, Y. E., Michor, F., and Pao, W. (2013). Epidermal Growth Factor Receptor Tyrosine Kinase Inhibitor-Resistant Disease. J. Clin. Oncol. 31, 1070-1080. doi:10.1200/jco.2012.43.3912

Ohoka, N., Tsuji, G., Shoda, T., Fujisato, T., Kurihara, M., Demizu, Y., et al. (2019a). Development of Small Molecule Chimeras that Recruit AhR E3 Ligase to Target Proteins. ACS Chem. Biol. 14, 2822-2832. doi:10.1021/acschembio. $9 \mathrm{~b} 00704$

Ohoka, N., Ujikawa, O., Shimokawa, K., Sameshima, T., Shibata, N., Hattori, T., et al. (2019b). Different Degradation Mechanisms of Inhibitor of Apoptosis Proteins (IAPs) by the Specific and Nongenetic IAP-dependent Protein Eraser (SNIPER). Chem. Pharm. Bull. 67, 203-209. doi:10.1248/cpb.c1800567

Petrylak, D. P., Gao, X., Vogelzang, N. J., Garfield, M. H., Taylor, I., Dougan Moore, M., et al. (2020). First-in-human Phase I Study of ARV-110, an Androgen Receptor (AR) PROTAC Degrader in Patients (Pts) with Metastatic CastrateResistant Prostate Cancer (mCRPC) Following Enzalutamide (ENZ) And/or Abiraterone (ABI). J. Clin. Oncol. 38, 3500. doi:10.1200/jco.2020.38.15_suppl. 3500

Pezzuto, A., and Carico, E. (2018). Role of HIF-1 in Cancer Progression: Novel Insights. A Review. Curr. Mol. Med. 18, 343-351. doi:10.2174/ 1566524018666181109121849

Potjewyd, F., Turner, A.-M. W., Beri, J., Rectenwald, J. M., Norris-Drouin, J. L., Cholensky, S. H., et al. (2020). Degradation of Polycomb Repressive Complex 2 with an EED-Targeted Bivalent Chemical Degrader. Cel Chem. Biol. 27, 47-56. doi:10.1016/j.chembiol.2019.11.006

Qi, S. M., Cheng, G., Cheng, X. D., Xu, Z., Xu, B., Zhang, W. D., et al. (2020). Targeting USP7-Mediated Deubiquitination of MDM2/MDMX-P53 Pathway for Cancer Therapy: Are We There yet?. Front Cel Dev Biol. 8, 233. doi:10.3389/ fcell.2020.00233 
Qin, J. J., Li, X., Wang, W., Zi, X., and Zhang, R. (2017). Targeting the NFAT1MDM2-MDMX Network Inhibits the Proliferation and Invasion of Prostate Cancer Cells, Independent of P53 and Androgen. Front. Pharmacol. 8, 917. doi:10.3389/fphar.2017.00917

Qin, J.-J., Wang, W., and Zhang, R. (2017). Experimental Therapy of Advanced Breast Cancer: Targeting NFAT1-MDM2-P53 Pathway. Prog. Mol. Biol. Transl Sci. 151, 195-216. doi:10.1016/bs.pmbts.2017.07.005

Qin, J.-J., Li, X., Hunt, C., Wang, W., Wang, H., and Zhang, R. (2018). Natural Products Targeting the P53-MDM2 Pathway and Mutant P53: Recent Advances and Implications in Cancer Medicine. Genes Dis. 5, 204-219. doi:10.1016/j.gendis.2018.07.002

Roskoski, R., Jr. (2020). Properties of FDA-Approved Small Molecule Protein Kinase Inhibitors: A 2020 Update. Pharmacol. Res. 152, 104609. doi:10.1016/j. phrs.2019.104609

Ryan, D., and Matthews, J. (2005). Protein-protein Interactions in Human Disease. Curr. Opin. Struct. Biol. 15, 441-446. doi:10.1016/j.sbi.2005. 06.001

Sakamoto, K. M., Kim, K. B., Kumagai, A., Mercurio, F., Crews, C. M., and Deshaies, R. J. (2001). Protacs: Chimeric Molecules that Target Proteins to the Skp1-Cullin-F Box Complex for Ubiquitination and Degradation. Proc. Natl. Acad. Sci. 98, 8554-8559. doi:10.1073/pnas. 141230798

Sakamoto, K. M., Kim, K. B., Verma, R., Ransick, A., Stein, B., Crews, C. M., et al. (2003). Development of Protacs to Target Cancer-Promoting Proteins for Ubiquitination and Degradation. Mol. Cell Proteomics. 2, 1350-1358. doi:10. 1074/mcp.t300009-mcp200

Schapira, M., Calabrese, M. F., Bullock, A. N., and Crews, C. M. (2019). Targeted Protein Degradation: Expanding the Toolbox. Nat. Rev. Drug Discov. 18, 949-963. doi:10.1038/s41573-019-0047-y

Shi, C., Zhang, H., Wang, P., Wang, K., Xu, D., Wang, H., et al. (2019). PROTAC Induced-BET Protein Degradation Exhibits Potent Anti-osteosarcoma Activity by Triggering Apoptosis. Cell Death Dis. 10, 815. doi:10.1038/s41419-0192022-2

Singh, R., Letai, A., and Sarosiek, K. (2019). Regulation of Apoptosis in Health and Disease: the Balancing Act of BCL-2 Family Proteins. Nat. Rev. Mol. Cel Biol. 20, 175-193. doi:10.1038/s41580-018-0089-8

Stathis, A., and Bertoni, F. (2018). BET Proteins as Targets for Anticancer Treatment. Cancer Discov. 8, 24-36. doi:10.1158/2159-8290.cd-170605

Su, S., Yang, Z., Gao, H., Yang, H., Zhu, S., An, Z., et al. (2019). Potent and Preferential Degradation of CDK6 via Proteolysis Targeting Chimera Degraders. J. Med. Chem. 62, 7575-7582. doi:10.1021/acs.jmedchem. $9 \mathrm{~b} 00871$

Sun, D. Y., Wu, J.-Q., He, Z.-H., He, M.-F., and Sun, H.-B. (2019). Cancerassociated Fibroblast Regulate Proliferation and Migration of Prostate Cancer Cells through TGF- $\beta$ Signaling Pathway. Life Sci. 235, 116791. doi:10.1016/j.lfs. 2019.116791

Sun, X., Gao, H., Yang, Y., He, M., Wu, Y., Song, Y., et al. (2019). PROTACs: Great Opportunities for Academia and Industry. Signal. Transduct Target. Ther. 4, 64. doi:10.1038/s41392-019-0101-6

Sun, X., and Rao, Y. (2020). PROTACs as Potential Therapeutic Agents for Cancer Drug Resistance. Biochemistry. 59, 240-249. doi:10.1021/acs. biochem.9b00848

Sun, Y., Zhao, X., Ding, N., Gao, H., Wu, Y., Yang, Y., et al. (2018). PROTACinduced BTK Degradation as a Novel Therapy for Mutated BTK C481S Induced Ibrutinib-Resistant B-Cell Malignancies. Cel Res. 28, 779-781. doi:10.1038/ s41422-018-0055-1

Toure, M., and Crews, C. M. (2016). Small-Molecule PROTACS: New Approaches to Protein Degradation. Angew. Chem. Int. Ed. 55, 1966-1973. doi:10.1002/anie. 201507978

Vollmer, S., Cunoosamy, D., Lv, H., Feng, H., Li, X., Nan, Z., et al. (2020). Design, Synthesis, and Biological Evaluation of MEK PROTACs. J. Med. Chem. 63, 157-162. doi:10.1021/acs.jmedchem.9b00810

Wang, L., Zhang, J., Wan, L., Zhou, X., Wang, Z., and Wei, W. (2015). Targeting Cdc20 as a Novel Cancer Therapeutic Strategy. Pharmacol. Ther. 151, 141-151. doi:10.1016/j.pharmthera.2015.04.002

Wang, W., Cheng, J.-W., Qin, J.-J., Hu, B., Li, X., Nijampatnam, B., et al. (2019). MDM2-NFAT1 Dual Inhibitor, MA242: Effective against Hepatocellular
Carcinoma, Independent of P53. Cancer Lett. 459, 156-167. doi:10.1016/j. canlet.2019.114429

Wang, X., He, Q., Wu, K., Guo, T., Du, X., Zhang, H., et al. (2019). Design, Synthesis and Activity of Novel 2,6-disubstituted Purine Derivatives, Potential Small Molecule Inhibitors of Signal Transducer and Activator of Transcription 3. Eur. J. Med. Chem. 179, 218-232. doi:10.1016/j.ejmech.2019. 06.017

Wang, W., Qin, J. J., Rajaei, M., Li, X., Yu, X., Hunt, C., et al. (2020a). Targeting MDM2 for Novel Molecular Therapy: Beyond Oncology. Med. Res. Rev. 40, 856-880. doi:10.1002/med.21637

Wang, W., Yang, J., Liao, Y.-Y., Cheng, G., Chen, J., Mo, S., et al. (2020b). Aspeterreurone A, a Cytotoxic Dihydrobenzofuran-Phenyl Acrylate Hybrid from the Deep-Sea-Derived Fungus Aspergillus terreus CC-S06-18. J. Nat. Prod. 83, 1998-2003. doi:10.1021/acs.jnatprod.0c00189

Winter, G. E., Buckley, D. L., Paulk, J., Roberts, J. M., Souza, A., Dhe-Paganon, S., et al. (2015). Phthalimide Conjugation as a Strategy for In Vivo Target Protein Degradation. Science. 348, 1376-1381. doi:10.1126/science. aab1433

Winzker, M., Friese, A., Koch, U., Janning, P., Ziegler, S., and Waldmann, H. (2020). Development of a PDE $\delta$-Targeting PROTACs that Impair Lipid Metabolism. Angew. Chem. Int. Ed. 59, 5595-5601. doi:10.1002/anie. 201913904

Wolska-Washer, A., and Robak, T. (2019). Safety and Tolerability of AntibodyDrug Conjugates in Cancer. Drug Saf. 42, 295-314. doi:10.1007/s40264-0180775-7

Wu, P., Nielsen, T. E., and Clausen, M. H. (2015). FDA-approved Small-Molecule Kinase Inhibitors. Trends Pharmacol. Sci. 36, 422-439. doi:10.1016/j.tips.2015. 04.005

Xu, J. L., Yuan, L., Tang, Y. C., Xu, Z. Y., Xu, H. D., Cheng, X. D., et al. (2020). The Role of Autophagy in Gastric Cancer Chemoresistance: Friend or Foe?. Front. Cel Dev Biol 8, 621428. doi:10.3389/fcell.2020.621428

Xue, G., Chen, J., Liu, L., Zhou, D., Zuo, Y., Fu, T., et al. (2020). Protein Degradation through Covalent Inhibitor-Based PROTACs. Chem. Commun. 56, 1521-1524. doi:10.1039/c9cc08238g

Yang, H., Lv, W., He, M., Deng, H., Li, H., Wu, W., et al. (2019). Plasticity in Designing PROTACs for Selective and Potent Degradation of HDAC6. Chem. Commun. 55, 14848-14851. doi:10.1039/c9cc08509b

Yu, D. H., Xu, Z. Y., Mo, S., Yuan, L., Cheng, X. D., and Qin, J. J. (2020). Targeting MDMX for Cancer Therapy: Rationale, Strategies, and Challenges. Front. Oncol. 10, 1389. doi:10.3389/fonc.2020.01389

Yuan, L., Xu, Z. Y., Ruan, S. M., Mo, S., Qin, J. J., and Cheng, X. D. (2020). Long Non-coding RNAs towards Precision Medicine in Gastric Cancer: Early Diagnosis, Treatment, and Drug Resistance. Mol. Cancer. 19, 96. doi:10. 1186/s12943-020-01219-0

Zhang, F., Wu, Z., Chen, P., Zhang, J., Wang, T., Zhou, J., et al. (2020). Discovery of a New Class of PROTAC BRD4 Degraders Based on a Dihydroquinazolinone Derivative and Lenalidomide/pomalidomide. Bioorg. Med. Chem. 28, 115228. doi:10.1016/j.bmc.2019.115228

Zhang, H., Zhao, H.-Y., Xi, X.-X., Liu, Y.-J., Xin, M., Mao, S., et al. (2020). Discovery of Potent Epidermal Growth Factor Receptor (EGFR) Degraders by Proteolysis Targeting Chimera (PROTAC). Eur. J. Med. Chem. 189, 112061. doi:10.1016/j.ejmech.2020.112061

Zhang, J., Wu, T., Simon, J., Takada, M., Saito, R., Fan, C., et al. (2018). VHL Substrate Transcription Factor ZHX2 as an Oncogenic Driver in Clear Cell Renal Cell Carcinoma. Science 361, 290-295. doi:10.1126/science. aap8411

Zhang, J., and Zhang, Q. (2018). VHL and Hypoxia Signaling: Beyond HIF in Cancer. Biomedicines. 6, 35. doi:10.3390/biomedicines6010035

Zhang, X., Thummuri, D., He, Y., Liu, X., Zhang, P., Zhou, D., et al. (2019). Utilizing PROTAC Technology to Address the On-Target Platelet Toxicity Associated with Inhibition of BCL-XL. Chem. Commun. 55, 14765-14768. doi:10.1039/c9cc07217a

Zhao, Q., Ren, C., Liu, L., Chen, J., Shao, Y., Sun, N., et al. (2019). Discovery of SIAIS178 as an Effective BCR-ABL Degrader by Recruiting Von Hippel-Lindau (VHL) E3 Ubiquitin Ligase. J. Med. Chem. 62, 9281-9298. doi:10.1021/acs. jmedchem.9b01264

Zhou, H., Bai, L., Xu, R., Zhao, Y., Chen, J., Mceachern, D., et al. (2019). StructureBased Discovery of SD-36 as a Potent, Selective, and Efficacious PROTAC 
Degrader of STAT3 Protein. J. Med. Chem. 62, 11280-11300. doi:10.1021/acs. jmedchem.9b01530

Zhou, F., Chen, L., Cao, C., Yu, J., Luo, X., Zhou, P., et al. (2020). Development of Selective Mono or Dual PROTAC Degrader Probe of CDK Isoforms. Eur. J. Med. Chem. 187, 111952. doi:10.1016/j.ejmech.2019.111952

Zhou, L., Chen, W., Cao, C., Shi, Y., Ye, W., Hu, J., et al. (2020). Design and Synthesis of a-naphthoflavone Chimera Derivatives Able to Eliminate Cytochrome P450 (CYP)1B1-mediated Drug Resistance via Targeted CYP1B1 Degradation. Eur. J. Med. Chem. 189, 112028. doi:10.1016/j.ejmech. 2019.112028

Zhou, Y., Chen, R., Luo, X., Zhang, W. D., and Qin, J. J. (2020). The E2 UbiquitinConjugating Enzyme UbcH5c: an Emerging Target in Cancer and Immune Disorders. Drug Discov. Today 25 (11), 1988-1997. doi:10.1016/j.drudis.2020. 09.015
Zou, Y., Ma, D., and Wang, Y. (2019). The PROTAC Technology in Drug Development. Cell Biochem Funct. 37, 21-30. doi:10.1002/cbf.3369

Conflict of Interest: The authors declare that the research was conducted in the absence of any commercial or financial relationships that could be construed as a potential conflict of interest.

Copyright (c) 2021 Qi, Dong, Xu, Cheng, Zhang and Qin. This is an open-access article distributed under the terms of the Creative Commons Attribution License (CC BY). The use, distribution or reproduction in other forums is permitted, provided the original author(s) and the copyright owner(s) are credited and that the original publication in this journal is cited, in accordance with accepted academic practice. No use, distribution or reproduction is permitted which does not comply with these terms. 